\title{
Design and comparison of printed antennas using meander line technique
}

\author{
Nur Hamizah Muhamad Mokhtar, Norun Abdul Malek, Ahmad Zamani Jusoh, Khamis Ali, Farah \\ Nadia Mohd Isa, Farah Diyana Abdul Rahman \\ Department of Electrical and Computer Engineering, International Islamic University Malaysia, Malaysia
}

\begin{tabular}{l}
\hline \hline Article Info \\
\hline Article history: \\
Received Jan 9, 2019 \\
Revised Mar 2, 2019 \\
Accepted Mar 25, 2019
\end{tabular}

Keywords:

Compact antenna

Meanderline

Printed dipole

Printed monopole

Small antenna

\begin{abstract}
The interest for compact antennas in wireless communication increase due to the portability and mobility of the communication devices. Generally, an antenna at low frequency exhibits in large physical size. This project investigates the design of an antenna at $400 \mathrm{MHz}$. The simulation of the antenna has been performed using CST MWS. Since medical applications are dealing with low frequency, it will lead to large size of antenna which brings a challenge for wireless personal area network (WPAN). It is well known that the antenna performance decreases (according to Chu's equation) as the size of antenna decreases. Therefore, antenna miniaturization using Meander Line (ML) will be taking place to overcome the challenges. Thus, this paper presents a comparison between i) printed dipole antenna without meander line technique, ii) printed dipole with meander line technique and iii) printed monopole antenna with meander line technique. The results show that an estimation of reduction size by $50 \%$ can be achieved using Meander Line technique.
\end{abstract}

Copyright (c) 2019 Institute of Advanced Engineering and Science. All rights reserved.

\section{Corresponding Author:}

Norun Abdul Malek,

Department of Electrical and Computer Engineering,

Kulliyyah of Engineering, International Islamic University Malaysia,

Kuala Lumpur, Malaysia.

Email: norun@iium.edu.my

\section{INTRODUCTION}

Miniaturization of wireless communication system have been favourable in conjunction with the high demand for small or compact equipment. Antenna also has no exemption. Small is defined in many ways. However, antenna is designed for the sake of comparison. Often, the antenna that has been reduced in size not compatible with their performance. To design a small antenna for low frequency in conventional method resulting in a large size of antenna. At low operating frequency, the issues comes in terms of it sizes as the antenna sizes affects the systems and portability [1].

The antenna is involved in many wireless electronic devices with a different kind of size. The attraction to the small antenna in this era increase due to fast-growth in an industry of mobile communications [2]. The demand not only involved the small size of an antenna, but the better performance and efficiency also must be considered in designing an antenna. However, due to the fundamental limitations in size and performance (Chu's limit), achieving miniaturization with good antenna performance is challenging. Electrically small antennas (ESAs) are limited in bandwidth and radiating efficiency. Thus, this factor should be taken into account when designing an antenna.

A small antenna can be defined in different wavelengths such as one-quarter wavelength (1/4), one-eight wavelength (1/8) or one-tenth wavelength (1/10). Not only that, it also can be defined in term of electrical size. A small antenna in electrical size or volume described by the value of $k a$ where $k$ is 
wavenumber of $2 \pi / \lambda$ in free space and $a$ is a radius of sphere in an imaginary circumscribing the maximum dimension of the antenna.

On the other hand, the miniaturization of antenna can be observed in a few methods. There are meander line techniques, fractals and using metamaterial. Each technique comes with its own advantages and disadvantages. Meander line was applied to increase the electrical length of the antenna as in [3] while fractal is proven to design antenna with multiband, wideband as well as to reduce the antenna size [2]. For metamaterial, multiband frequency can be achieved as well as reduce the antenna size as in [4].

Meander-line antenna concept is to fold the conductors back and forth in order to produce a compact antenna with shorter length. The limitation of the area size for antenna placement brings challenge to the antenna designer. Thus, other than using the structure of meander-line to the antenna itself, it is also has been implemented at the reactive impedance surface (RIS) of the metallic ground of the antenna as in [5]. This technique allows size reduction of $25 \%-50 \%$ of the antenna original size. By using meander-line design, antenna can be operated at low frequency such as at $315 \mathrm{MHz}$ [6]. Meander line antenna is used as from [7], a half wavelength dipole is made compact by meandering the wire [8]. Same approach can be applied to design a meander-type slot antenna for size reduction up to 80\% [9-10]. Other than that, meandering the excited patch surface current paths in the microstrip antenna's radiating patch is also an effective method for achieving a lowered fundamental resonant frequency for the microstrip antenna [11-15]. From this fact, meander type antenna has some advantages such as compact size/small, easily integrated into wireless devices, and low cost implementation [16]. Miniaturization method of printed meander-line is used in the design. Printed antennas has been favoured because it is able to minimize the space, light weight, and minimum cost required for the production. For the past twenty years ago, printed antenna features was studied and evolved until today [1, 16-17]. On the other hand, Meander Line techniques has been applied in telemetry applications [18].

It is well known that electrically small antennas suffers the fundamental limit of high $Q$ and can not be used for broadband radiation in conventional cases. It is highlighted that as the antenna size decreases, antenna performance such as bandwidth and efficiency will be affected due to the $Q$ 's formula as in (1).

$$
Q_{c h u}=\frac{1}{(k a)^{3}}+\frac{1}{k a}
$$

$Q$ refers to quality factor and high $Q$ refers to narrowband antenna. As the size of antenna $k a$ decreases, $Q$ values will increase thus leading to a narrow bandwidth antenna.

In this paper, a few design of printed antennas with a meander line technique at $400 \mathrm{MHz}$ is simulated and fabricated to study its performance. This paper proposed three antenna designs which are printed dipole antenna (without Meander-Line), printed dipole antenna (with Meander-Line [19]) and monopole antenna (with Meander-Line). The objective is to investigate the size that can be reduced from the normal design using miniaturization technique and compare their performance. The operating frequency is at $400 \mathrm{MHz}$. The following section will discuss the antenna design consideration and some simulated and measurement results e.g. return loss (S11), bandwidth, and radiation pattern.

\section{RESEARCH METHOD}

\subsection{Printed dipole antenna}

Simulation of a printed dipole antenna (without meander line) was performed in CST MW. The proposed antennas are printed on a FR- 4 substrate as the material with dielectric constant is 4.3 and thickness of $1.6 \mathrm{~mm}$. The antennas were modeled using copper (annealed) which is a lossy material. Copper (annealed) is chosen as it corresponds with the practical antenna so the results will be presented close to actual values.

The printed dipole is fed with the gap G between the two dipole arms. In this case, the suitable gap $\mathrm{G}$ has been chosen. This antenna was simulated for the comparison of its performance and the resulting size observed. It is observed that from the printed dipole antenna design at $400 \mathrm{MHz}$ as shown in Figure 1 and 2 , the size is quite high which is around $(44 \mathrm{~cm} \mathrm{x} 16 \mathrm{~cm})$. Therefore, a meander line technique has been proposed to reduce the size of printed dipole antenna. The dimension is shown in Table 1. 
Table 1. Printed dipole antenna parameter [19]

\begin{tabular}{lcc}
\hline \multicolumn{1}{c}{ Antenna design parameter } & Value & Unit \\
\hline Resonant frequency, $f$ & 0.4 & $\mathrm{GHz}$ \\
Length dipole, $L_{l}$ & 389.08 & $\mathrm{~mm}$ \\
Length substrate, $L_{s}$ & 440.00 & $\mathrm{~mm}$ \\
Height substrate, $H_{s}$ & 160.00 & $\mathrm{~mm}$ \\
Dipole arm length, $L_{a}=L_{b}=\lambda / 4$ & 192.54 & $\mathrm{~mm}$ \\
Microstrip line width, $W$ & 18.00 & $\mathrm{~mm}$ \\
dielectric constant (FR4), $\varepsilon_{r}$ & 4.30 & - \\
Patch thickness (copper annealed), $t$ & 0.035 & $\mathrm{~mm}$ \\
Antenna feed gap, $G$ (approximation) & 4.00 & $\mathrm{~mm}$ \\
Substrate thickness, $h$ & 1.60 & $\mathrm{~mm}$ \\
\hline
\end{tabular}



(a)

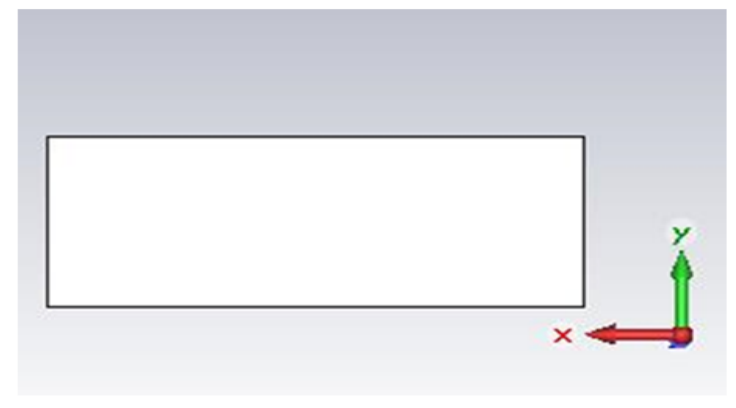

(b)

Figure 1. (a) Top view, (b) back view of printed dipole antenna [19]

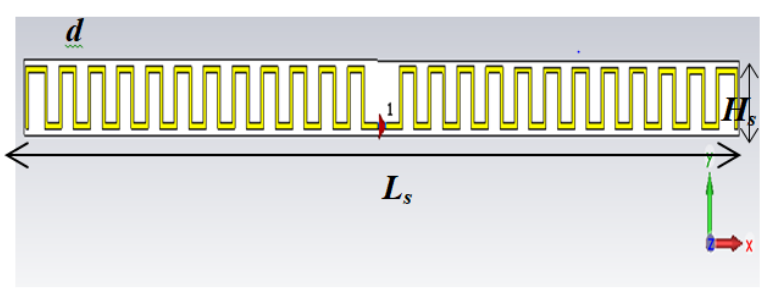

(a)

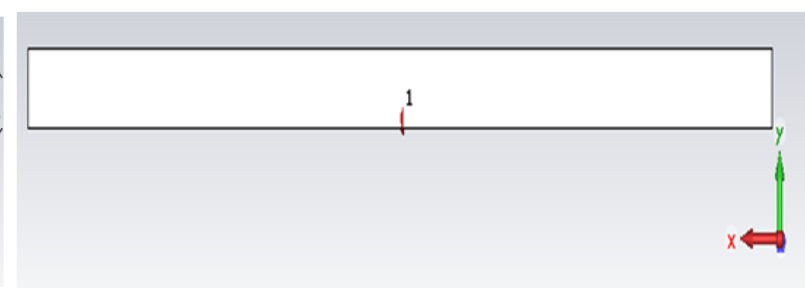

(b)

Figure 2. (a) Top view, (b) back view of printed meander-line dipole antenna [19]

\subsection{Printed dipole antenna with meander line technique}

Simulation of a printed dipole antenna with Meander-Line technique is applied for miniaturization process. The length of dipole antenna is folded back and forth in order to reduce the dipole arm's length. Using the dimensions in Table 2, a printed dipole antenna of meander line (ML) technique at $400 \mathrm{MHz}$ has been designed using CST as shown in Figure 2 and Figure (a) and (b). It is observed that the size of meander line printed dipole antenna has been reduced to $24 \mathrm{~cm} \mathrm{x} 12 \mathrm{~cm}$ which is approximately reduced to half from the initial design of printed dipole antenna as shown in Figure 1.

Table 2. Printed dipole antenna (half wavelength) dimensions with meander-line antenna [19]

\begin{tabular}{lcc}
\hline \multicolumn{1}{c}{ Antenna design parameter } & Value & Unit \\
\hline Resonant frequency, $f$ & 0.4 & $\mathrm{GHz}$ \\
Length, $L$ & 247.0 & $\mathrm{~mm}$ \\
Distance between folded meander, $d$ & 6.0 & $\mathrm{~mm}$ \\
Length $S$, & 9.0 & $\mathrm{~mm}$ \\
Meander line width, $W$ & 1.0 & $\mathrm{~mm}$ \\
Patch thickness (copper annealed), $t$ & 0.035 & $\mathrm{~mm}$ \\
Antenna feed gap, $G$ (approximation) & 3.0 & $\mathrm{~mm}$ \\
Substrate thickness, $h$ & 1.6 & $\mathrm{~mm}$ \\
Height substrate, $H_{s}$ & 12.0 & $\mathrm{~mm}$ \\
Length substrate, $L_{s}$ & 248.0 & $\mathrm{~mm}$ \\
Dielectric constant (FR4), $\varepsilon_{r}$ & 4.3 & - \\
\hline
\end{tabular}




\subsection{Printed monopole antenna with meander line technique}

The monopole meander line antenna has been designed from the second simulation of meander line dipole antenna in section 2.1.2. As we want the antenna design to be smaller in size, therefore monopole antenna is considered in this case. The design initially taken from one side of the meander dipole arm. Thus, making the design exhibits as monopole. Monopole antenna are half size of the dipole antenna. The different of monopole antenna is that the design is mounted above some sort of ground plane that acts as a dipole due to the reflections. A printed meander line monopole antenna designed at $400 \mathrm{MHz}$ (Figure 3(a) and (b)) has been designed with the dimension shown in Table 3. It is observed that the size has been reduced to $13.65 \mathrm{~cm}$ $\mathrm{x} 2.7 \mathrm{~cm}$ which is much smaller than Figure 2 .

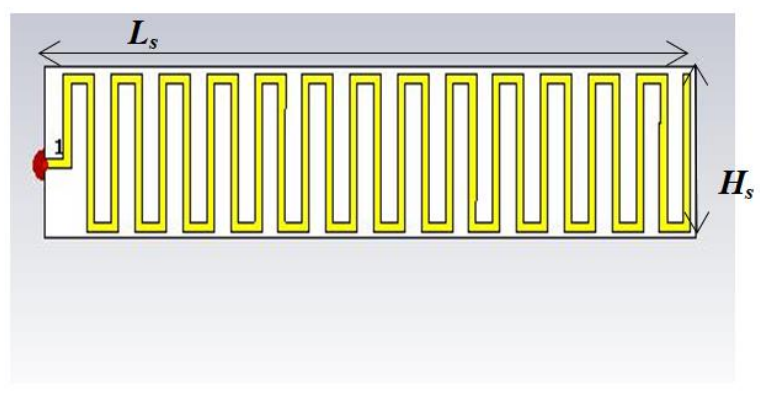

(a)

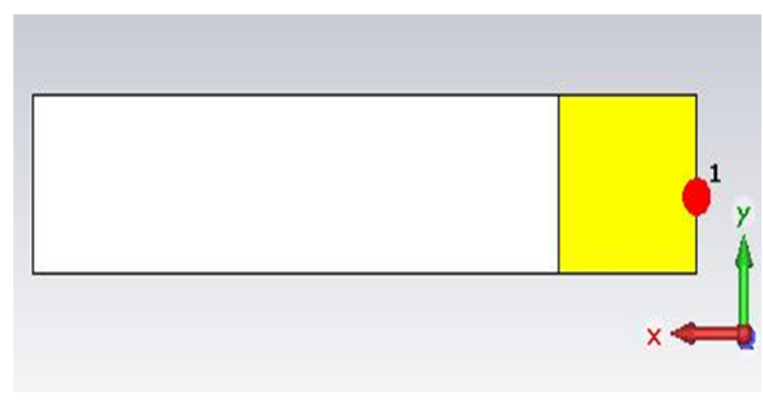

(a)

Figure 3. (a) Top view, (b) back view of printed meander-line monopole antenna [19]

Table 3. Monopole antenna (quarter wavelength) dimensions with meander-line antenna [19]

\begin{tabular}{lll}
\hline Antenna design parameter & Value & Unit \\
\hline Resonant frequency, $f$ & 0.4 & $\mathrm{GHz}$ \\
dielectric constant (FR4), $\varepsilon_{r}$ & 4.3 & - \\
Length of substrate, $L_{s}$ & 136.50 & $\mathrm{~mm}$ \\
Height substrate, $H_{s}$ & 27.0 & $\mathrm{~mm}$ \\
Length of ground plane, $L_{g}$ & 30.0 & $\mathrm{~mm}$ \\
Distance between folded meander, $d$ & 6.0 & $\mathrm{~mm}$ \\
Length, $S$ & 25.0 & $\mathrm{~mm}$ \\
Meander line width, $W$ & 1.5 & $\mathrm{~mm}$ \\
Patch thickness (copper annealed), $t$ & 0.035 & $\mathrm{~mm}$ \\
Substrate thickness, $h$ & 1.6 & $\mathrm{~mm}$ \\
\hline
\end{tabular}

\section{RESULTS AND ANALYSIS}

\subsection{Simulation results}

Figure 4 shows that each antenna design (design A, B and C) has the ability to resonate at $0.4 \mathrm{GHz}$. From the simulated data, by miniaturizing the antenna size, we can obtain a good antenna performance by using meander-line technique. The comparison of simulation results from three antenna designs are shown in Table 4. In our design, all the return loss $\left(S_{11}\right)$ values are higher than $10 \mathrm{~dB}$. Printed dipole (without ML-design A) shows return loss value of $40.22 \mathrm{~dB}$, printed dipole (with ML-design B) is $19.6 \mathrm{~dB}$ and monopole (with ML-design C) is $11.88 \mathrm{~dB}$. In terms of the antenna size, third antenna exhibits smaller size $(13.65 \mathrm{~cm} \times 2.7 \mathrm{~cm})$ compared to first $(44 \mathrm{~cm} \times 16 \mathrm{~cm})$ and second antenna $(24.8 \mathrm{~cm} \times 1.2 \mathrm{~cm})$. The third antenna exhibits nearly $75 \%$ reduction in comparison with the second (50\% reduction) based on the first design. However, the return loss decreased as the antenna size decreased. It is due to the electrically size decrease the radiation resistance and resulting to lower value of return losses as in Figure 4.

In terms of bandwidth, the results exhibit the same behavior which is the largest bandwidth is obtained from printed dipole antenna (22\%), followed by printed meanderline dipole antenna $(8.2 \%)$ and the smallest bandwidth is the printed meanderline monopole antenna $(2.1 \%)$. It is in accordance to the theory of Chu's limit that as antenna size decreases, the $Q$ factor increases which lead to low bandwidth of the antenna.

Figure 5 and 6 shows the combination of all three simulated design radiation pattern in two-dimensional pattern. It is observed that the pattern is circular shape (omni-directional) on the azimuth plane (phi=90) as well as eight-shape pattern on the elevation plane (theta=90). The radiation pattern for all the antenna shows (omni-directional) pattern where the radiating energy is almost the same in all directions in that plane. 




Figure 4. $S_{11}$ curves for antenna A (green line), B (red line) and C (blue line) [19]

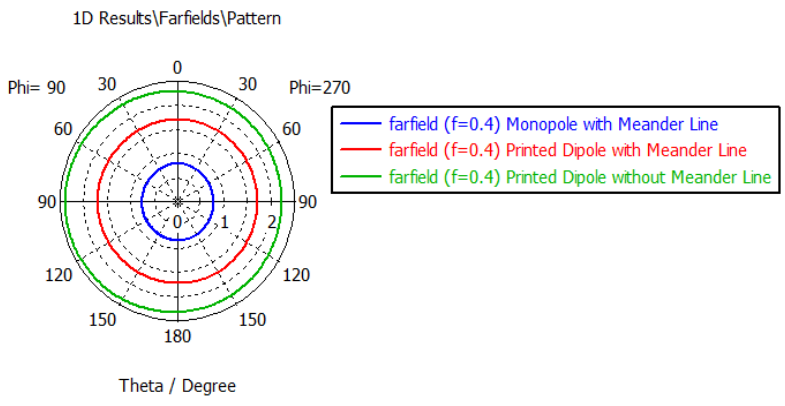

Figure 5. Radiation pattern of three antennas cut at azimuth plane [19]



Figure 6. Radiation pattern elevation plane [19]

Table 4. Comparison of antenna performance for each of the proposed design [19]

\begin{tabular}{cccc}
\hline Parameters & $\begin{array}{c}\text { Printed dipole antenna } \\
\text { (Antenna A) }\end{array}$ & $\begin{array}{c}\text { Printed meander-line dipole antenna } \\
\text { (Antenna B) }\end{array}$ & $\begin{array}{c}\text { Printed meander-line monopole antenna } \\
\text { (Antenna C) }\end{array}$ \\
\hline Resonant Frequency & $400 \mathrm{MHz}$ & $400 \mathrm{MHz}$ & $400 \mathrm{MHz}$ \\
Return loss & $40.22 \mathrm{~dB}$ & $19.60 \mathrm{~dB}$ & $11.88 \mathrm{~dB}$ \\
$\left(\mathrm{~S}_{11}\right)$ & & $0.0327 \mathrm{GHz}(8.2 \%)$ & $0.0084 \mathrm{GHz}(2.1 \%)$ \\
Bandwidth & $0.087 \mathrm{GHz}(22 \%)$ & $2.014 \mathrm{dBi}$ & $1.918 \mathrm{dBi}$ \\
Directivity & $2.3 \mathrm{dBi}$ & Omni-directional & Omni-directional \\
Radiation pattern & Omni-directional & $248 \mathrm{~mm} * 12 \mathrm{~mm} * 1.635 \mathrm{~mm}$ & $136.50 \mathrm{~mm} * 27 \mathrm{~mm} * 1.67 \mathrm{~mm}$ \\
Dimension & $440 \mathrm{~mm} * 160 \mathrm{~mm} * 1.635 \mathrm{~mm}$ & $0.69 *$ dielectric wavelength & $0.38 *$ dielectric wavelength \\
Electrical length & $1.22 *$ dielectric wavelength & &
\end{tabular}

\subsection{Measurement results}

Design of $\mathrm{B}$ and $\mathrm{C}$ have been fabricated in order to validate the $\mathrm{S}_{11}$ performance of the simulation design. The designs as shown in Figure 7 and 8 were measured using Vector Network Analyser and the comparison between simulation and measurement results have been plotted in Figure 9. Table 5 summarizes the perofmance of both designs. It was observed that Design B has a close agreement between simulation and measurement results in comparison with Design C. One of the disagreements of Design C is due to the fact that it is fabricated manually, from film printing, patching, UV exposure, etching, cutting and finishing process which lead to the inaccuracies of the design. Thus, Table 5 illustrated the comparison of simulation and measurement results between design $\mathrm{B}$ and $\mathrm{C}$.

Table 5. Comparison of $\mathrm{S}_{11}$ parameters of design B and C

\begin{tabular}{ccccc}
\hline Parameters & \multicolumn{2}{c}{ Design B } & \multicolumn{2}{c}{ Design C } \\
\hline & Simulation & Measurement & Simulation & Measurement \\
Resonant frequency & $0.40 \mathrm{GHz}$ & $0.343 \mathrm{GHz}$ & $0.40 \mathrm{GHz}$ & $0.40 \mathrm{GHz}$ \\
Return Loss & $19.6 \mathrm{~dB}$ & $17.73 \mathrm{~dB}$ & $11.88 \mathrm{~dB}$ & $7 \mathrm{~dB}$ \\
Bandwidth & $0.0327 \mathrm{GHz}(8.2 \%)$ & $0.0252 \mathrm{GHz}(6.3 \%)$ & $0.0084 \mathrm{GHz}(2.1 \%)$ & - \\
\hline
\end{tabular}






(a)

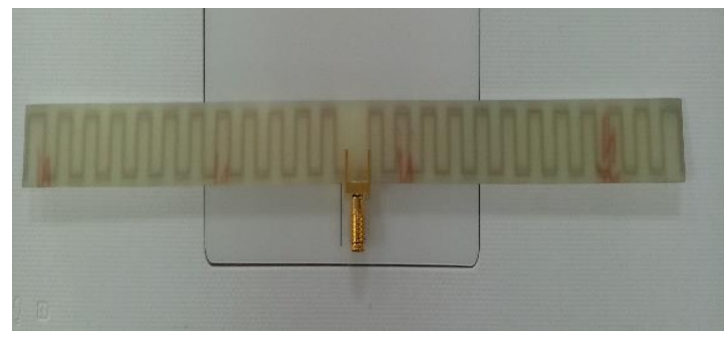

(b)

Figure 7. Fabricated design of printed dipole antenna (with ML technique), (a) top view, (b) back view [19]

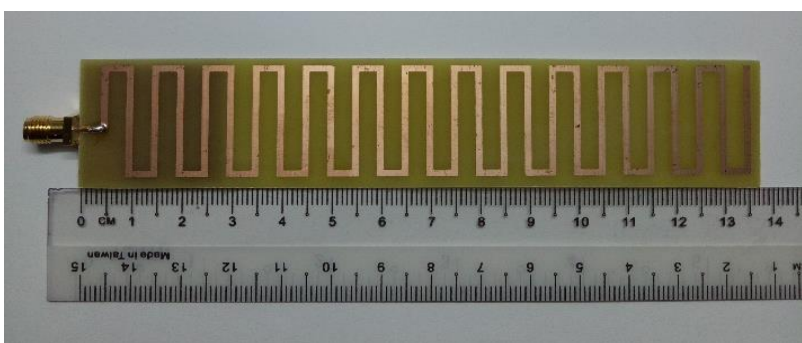

(a)

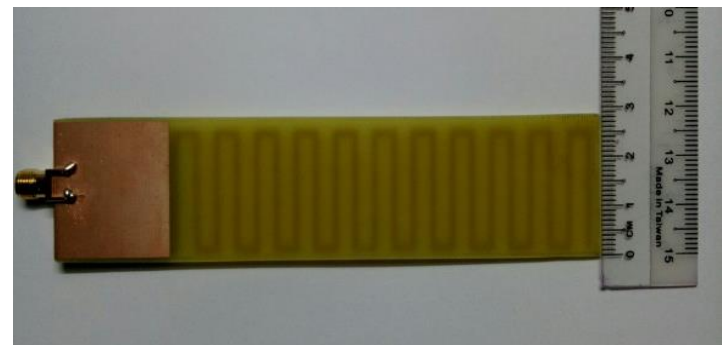

(b)

Figure 8. Fabricated design of printed monopole antenna (with ML technique), (a) top view, (b) back view

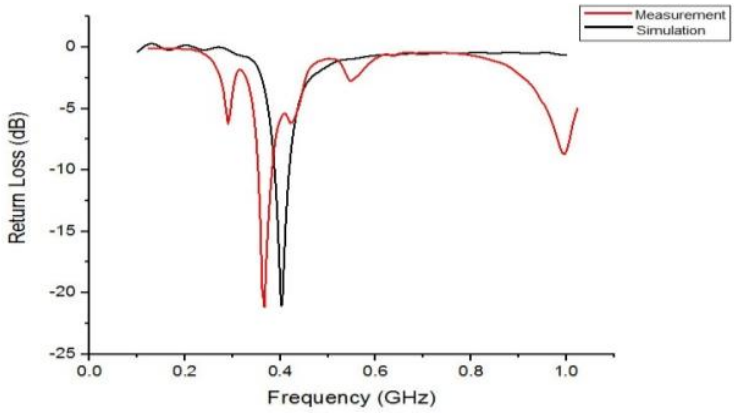

(a)



(b)

Figure 9. Comparison of $S_{11}$ parameters between simulation (black curve) and measurement results (red curve), (a) Design B of printed dipole antenna using meanderline technique [19], (b) Design C of printed monopole antenna using meanderline technique

\section{CONCLUSION}

The miniaturization antenna using Meander Line (ML) technique has been performed and investigated in detail. This research investigates on how much antenna size can be reduced using Meander Line (ML) technique and at the same time able to resonate at the required frequency. The simulated results shows that the three proposed design are able to operate at the desired frequency of $400 \mathrm{MHz}$. Based on the $\mathrm{S} 11$, it is observed that as the antenna size reduces, the antenna performance decreases especially in terms of return loss and bandwidth according to Chu's equation.

Thus, based on the S11 results, design B of printed dipole and design $\mathrm{C}$ of printed monopole antennas (with ML) were fabricated to validate the antenna performances. Design $\mathrm{C}$ was fabricated manually leading to inaccuracies between simulation and measurement results. Although the fabricated antenna with the simulated both did not agree with one another due to the losses, tolerance as well as fabrication error when constructing the antenna, it can be seen that using Meander Line the antenna size can be reduced.

For the further improvement, the antenna size can be further decreased using other miniaturization techniques. Other types of miniaturization technique can be reviewed in depth in order to have an antenna with compact size and good performance at low frequency. 


\section{ACKNOWLEDGEMENTS}

This research was supported by Research Initiative Grant Scheme (RIGS 2016), International Islamic University Malaysia.

\section{REFERENCES}

[1] M. O. F. Howlader and T. P. Sattar, "Miniaturization of Dipole Antenna for Low Frequency Ground Penetrating Radar," Progress In Electromagnetics Research C, vol. 61, pp. 161-170, 2016.

[2] D. Werner and S. Ganguly, "An overview of fractal antenna engineering research", in IEEE Antennas and Propagation Magazine, vol. 45, no. 1, pp. 38-57, 2003.

[3] G. León, R. Boix and F. Medina, "A comparison among different reduced-size resonant microstrip patches", Microwave and Optical Technology Letters, vol. 29, no. 3, pp. 143-146, 2001.

[4] N. Kulkarni and G. Lohiya, "A Compact Microstrip Patch Antenna using Metamaterial", International Journal of Engineering Trends and Technology, vol. 42, no. 7, pp. 365-369, 2016.

[5] A. Ghosh, A. Mitra and S. Das, "Meander line-based low profile RIS with defected ground and its use in patch antenna miniaturization for wireless applications", Microwave and Optical Technology Letters, vol. 59, no. 3, pp. 732-738, 2017.

[6] A. An, T. Yoshimasu, K. Yamaoka and S. Kurachi, "A Novel Microstrip Meander-Line Antenna With A Very High Relative Permittivity Substrate For 315-MHz Band Applications," 2006 7th International Symposium on Antennas, Propagation \& EM Theory, Guilin, 2006, pp. 1-3.

[7] J. Rashed and C. -. Tai, "A new class of resonant antennas," in IEEE Transactions on Antennas and Propagation, vol. 39, no. 9, pp. 1428-1430, Sept. 1991.

[8] Jung-Min Kim, Jong-Gwan Yook, Woo-Young Song, Young-Joong Yoon, Jae-Yeong Park and Han-Kyu Park, "Compact meander-type slot antennas," IEEE Antennas and Propagation Society International Symposium. 2001 Digest. Held in conjunction with: USNC/URSI National Radio Science Meeting (Cat. No.01CH37229), Boston, MA, USA, 2001, pp. 724-727 vol.2.

[9] S. Dey and R. Mittra, "Compact microstrip patch antenna, " Microwave and Optical Technology Letters, vol. 13, no. 1, pp.12-14, 1996.

[10] L. Deng, S. Li, K. Lau and Q. Xue, "Vertical Meandering Approach for Antenna Size Reduction", International Journal of Antennas and Propagation, vol. 2012, pp. 1-5, 2012.

[11] K. L. Wong, C. L. Tang, and H. T. Chen, "A compact meandered circular microstrip antenna with a shorting pin," Microwave and Optical Technology Letters, vol. 15, no. 3, pp.147-149, 1997.

[12] C. K. Wu, K. L. Wong, and W. S. Chen, "Slot-coupled meandered microstrip antenna for compact dual-frequency operation," Electronics Letters, vol. 34, no. 11, pp. 1047-1048,1998.

[13] J. H. Lu and K. L. Wong, "Slot-loaded, meandered rectangular microstrip antenna with compact dual-frequency operation," Electronics Letters, vol. 34, no. 11, pp. 1048-1050, 1998.

[14] J. George, M. Deepukumar, C. K. Aanandan, P. Mohanan, and K. G. Nair, "New compact microstrip antenna," Electronics Letters, vol. 32, no. 6, pp. 508-509, 1996.

[15] O. Losito, M. Gallo, V. Dimiccoli, D. Barletta, M. Bozzetti, "Transmission Line Model For Meander Antennas," Proceedings of European Conference on Antennas and Propagation (EuCAP), Apr. 2010, pp. 1-4.

[16] C. Balanis., Antenna theory: analysis and design, 4th ed. Hoboken, United States: John Wiley \& Sons, 2016.

[17] Choudhary, A., Gopal, K., Sood, D., \& Tripathi, C. "Development of compact inductive coupled meander line RFID tag for near-field applications," International Journal of Microwave and Wireless Technologies, vol. 9, no. 4, pp. 757-764, 2017.

[18] N. H. Sulaiman, N. A. Samsuri, M. K. A. Rahim, F. C. Seman and M. Inam, "Compact Meander Line Telemetry Antenna for Implantable Pacemaker Applications", Indonesian Journal of Electrical Engineering and Computer Science (IJEECS), vol. 10, no. 3, pp. 883-889, June 2018.

[19] N. A. Malek, N. H. M. Mokhtar, K. Ali, F. N. M. Isa and F. D. A. Rahman, "Design of Small Antennas for 400 MHz Applications," 2018 7th International Conference on Computer and Communication Engineering (ICCCE), Kuala Lumpur, 2018, pp. 99-103.

\section{BIOGRAPHIES OF AUTHORS}

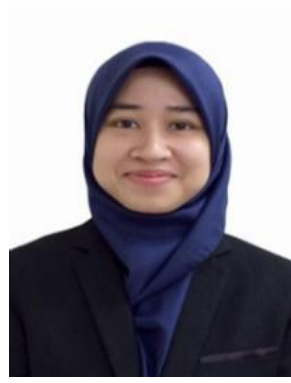

Nur.Hamizah.Muhamad.Mokhtar. started her foundation based program on 2012 at Center for Foundation studies, Petaling Jaya (CFS IIUM) in Engineering. Continuing her interest in Electric \& Electronic field, she continued her studies in this field and received a Bachelor of Engineering (Hons.), Communication Engineering in 2018 from International Islamic University Malaysia (IIUM). She is currently working in Semiconductor field company and also registered member of Board of Engineering Malaysia (BEM). 


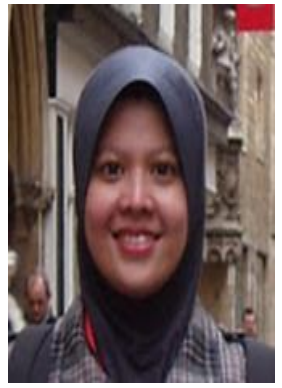

Norun Abdul Malek has been appointed as an assistant lecturer in 2006 and currently serves as Assistant Professor in the Department of Electrical and Computer Engineering, Faculty of Engineering, International Islamic University Malaysia (IIUM). Norun lectures on subjects in Fundamental of Communication Engineering, Digital Signal Processing, Signals and Systems, RF design, Antenna and Propagation for undergraduate and postgraduate levels, at the Department of Electrical and Computer Engineering. Her research interests are in the area of Numerical analysis especially in antenna arrays, signal processing and optimization techniques. Her research area also does not limit to wearable antennas and antennas using metamaterials for wireless communications. Norun received a MSc. degree in Digital Communication Systems from the Loughborough University, UK and a Ph.D. degree in Electrical and Electronic Engineering from the same university in 2008 in 2013, respectively. She is also a member of the IEEE, and IEM, and registered under the Board of Engineering Malaysia.



Ahmad Zamani Jusoh obtained his Bsc in Electronic Eng. From Hanyang University, Korea in 1999 and completed his Msc in Digital Communication Systems at Loughborough University, UK in 2002. He received PhD in Communication Engineering for The University of Western Australia, Australia in 2012. He is currently an assistant professor at faculty of engineering, International Islamic University Malaysia (IIUM). His research interest are in signal and speech analysis, wireless communication and IoT. He is a member of BEM.



Khamis Ali received his B.Eng. (hons) (2016). and M.S (2018) in communication engineering from International Islamic University Malaysia (IIUM). From Sept 2016 to June 2018, he worked as part-time teaching assistant at IIUM University. Then he joined MJIIT-UTM and worked as research assistant under project title Implantable Patch Antenna for Body Communication from August 2018 to October 2018.

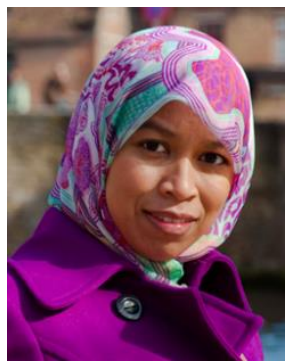

Farah Mohd Isa is a Senior Lecturer in Department of Electrical \& Computer Engineering, International Islamic University Malaysia. She obtained her $\mathrm{PhD}$ from University College London in 2013 working on the antenna design of a geophysical avalanche radar. She has received numerous scholarships for her academic excellence from Telekom Malaysia, Ministry of Higher Education Malaysia and UCL. Since returning back from her $\mathrm{PhD}$, she has been actively involved with the think tank group of creating climate resilient cities in Malaysia an effort from SEADPRI-UKM and NADMA. She then re-aligned her focus to help the communities affected by landslide by developing tools to predict the event of landslide as an early warning system. Her current research is now focused on applying a new generation of radar; software-defined radar to understanding and predicting landslide susceptibility. She has received RAGS, RIGS and FRGS (total RM 150,000) grants from the Ministry of Higher Education to help support her current research. She is an MIEEE and MIET member.



Farah Diyana Abdul Rahman obtained her PhD degree from Department of Electrical and Electronic Engineering, University of Bristol, UK in 2015. She has been appointed as an Assistant Professor in Electrical and Computer Engineering Department, Faculty of Engineering, International Islamic University Malaysia (IIUM). Her research interest includes image and video processing, video quality evaluation, multimedia transmission and wireless communication systems. She is an active member of the IEEE, a registered member of the Board of Engineers Malaysia (BEM) and Institute of Engineers Malaysia (IEM). 